\title{
Diacronie
}

Studi di Storia Contemporanea

$N^{\circ} 36,4 \mid 2018$

Viaggi e turismo nell'Europa del Novecento

\section{Actualidad del Turismo Rural en Europa: Andalucía y el Reino de Noruega, un estudio comparativo}

\section{Gloria Priego-De-Montiano}

\section{OpenEdition}

1 Journals

\section{Edición electrónica}

URL: https://journals.openedition.org/diacronie/10699

DOI: 10.4000/diacronie.10699

ISSN: 2038-0925

Editor

Association culturelle Diacronie

Referencia electrónica

Gloria Priego-De-Montiano, «Actualidad del Turismo Rural en Europa: Andalucía y el Reino de Noruega, un estudio comparativo», Diacronie [En línea], № 36, 4 | 2018, documento 13, Publicado el 29 diciembre 2018, consultado el 17 febrero 2022. URL: http://journals.openedition.org/diacronie/10699 ; DOI: https://doi.org/10.4000/diacronie.10699 


\section{Diacronie}

Studi di Storia Contemporanea

$36,4 / 2018$

Viaggi e turismo nell'Europa del Novecento

\section{Actualidad del Turismo Rural en Europa: Andalucía y el Reino de Noruega, un estudio comparativo}

Gloria PRIEGO-DE-MONTIANO

Per citare questo articolo:

PRIEGO-DE-MONTIANO, Gloria, «Actualidad del Turismo Rural en Europa: Andalucía y el Reino de Noruega, un estudio comparativo», Diacronie. Studi di Storia Contemporanea : Viaggi e turismo nell'Europa del Novecento, 36, 4/2018, 29/12/2018

URL: < http://www.studistorici.com/2018/12/29/priego-de-montiano_numero_36/ >

Diacronie Studi di Storia Contemporanea $\rightarrow$ http://www.diacronie.it Rivista storica online. Uscita trimestrale.

redazione.diacronie@hotmail.it

Comitato di direzione: Naor Ben-Yehoyada - João Fábio Bertonha - Christopher Denis-Delacour - Maximiliano Fuentes Codera Anders Granås Kjøstvedt - John Paul Newman - Deborah Paci - Niccolò Pianciola - Spyridon Ploumidis - Wilko Graf Von Hardenberg

Comitato di redazione: Jacopo Bassi - Luca Bufarale - Gianluca Canè - Luca G. Manenti - Fausto Pietrancosta - Alessandro Salvador - Matteo Tomasoni - Luca Zuccolo Creative Commons 3.0. Possono essere riprodotti e modificati a patto di indicare eventuali modifiche dei contenuti, di riconoscere la paternità dell'opera e di condividerla allo stesso modo. La citazione di estratti è comunque sempre autorizzata, nei limiti previsti dalla legge. 


\title{
13/ Actualidad del Turismo Rural en Europa: Andalucía y el Reino de Noruega, un estudio comparativo ${ }^{1}$
}

\author{
Gloria PRIEGO-DE-MONTIANO
}

Desde la planificación y normativa europea, sobre el sector productivo del Turismo Rural, se analizan diferentes aspectos de su crecimiento, proliferación, desarrollo, características y potencialidad, en la Europa Septentrional y Meridional: centrado ello en dos núcleos poblacionales tan distantes, en cuanto a estructura socioeconómica y cultural, como lo es Noruega, tal que foco representativo del fructífero crecimiento escandinavo, y Andalucía, Comunidad Autónoma española con extensas áreas de explotación dedicadas a esta nueva franja productiva de la industria turística, estando implicada, simultáneamente, en un proceso de reconversión agrícola-ganadero. El análisis de los dos casos de estudio fijados se centra específicamente en un cotejo de la evolución seguida en la implantación del nicho de productivo del Turismo Rural y las consecuencias socioeconómicas y culturales de su establecimiento y trayectoria.

\section{Introducción}

En principio podría parecer aleatorio la selección de los dos elementos comparativos de estudio, Noruega y Andalucía, dado su diferente perfil geográfico, socioeconómico y cultural; no obstante, la coincidencia en ambos casos de la pervivencia de similares problemáticas endémicas, en torno al territorio, como lo son el descenso de la población rural y la consecuente desestructuración territorial, con lo que ello supone para un desarrollo económico equilibrado, justificaría el enfoque comparativo, para el particular. De ahí que la propia Unión Europea, ante problemáticas de tal calibre, que a su vez afectan a la estabilidad de su territorio - no hay que olvidar que Noruega está ligada al espectro del Espacio Económico Europeo -, este poniendo

\footnotetext{
${ }^{1}$ El presente trabajo está enmarcado en la labor de investigación desarrollada para el Proyecto «Mujeres y Turismo Rural en España. Una propuesta de investigación, acciones de fomento y sensibilización», en convocatoria oficial de resultas del «Memorándum de Acuerdo sobre la Aplicación del Mecanismo Financiero del Espacio Económico Europeo de 2009-2014, entre el Reino de Noruega, Islandia y el Principado de Liechtenstein, y el Reino de España».
} 
énfasis en atajar tamaño obstáculo. Y es por ello, fundamentalmente, que se ha emprendido una intensiva acción política, en aras del fomento y apoyo del sector productivo entorno al Turismo Rural. De forma que, partiendo de los análisis de rigor, se ha puesto de manifiesto que, entre el despliegue de variables que rodean a la cuestión, la de género constituye un factor clave para el arraigo, sostenibilidad y diversificación del mencionado sector.

\section{Algunos condicionantes del «modelo» socioeconómico noruego}

Lo que se ha dado en llamar «el modelo noruego»², que arroja cifras socioeconómicas claves, y tan distantes de las españolas, como el sostener una tasa de desempleo de algo más del 3\%, con una afiliación sindical entorno al $53,5 \%^{3}$, y mantener superávit presupuestario, por citar algunas ${ }^{4}$; ha llegado a suscitar multitud de estudios comparativos, con el resto de países que engloban la Organización para la Cooperación y el Desarrollo Económico (OCDE). Lo que ha dado lugar, incluso, a preguntarse si es que ostenta un diferente «modelo de bienestar» ${ }^{5}$. Al punto de calificar, alguna de estas investigaciones, a la sociedad noruega, como "prospera, moderna y funcional», además de «país fuertemente igualitario» ${ }^{6}$. Y se destaca aquí el aspecto igualitario, enfocado al Turismo Rural, ya que hay que considerar, además, que la propia OCDE ha señalado la «igualdad» como un factor fundamental para el crecimiento ${ }^{7}$; siendo, así, varios los datos desagregados que se destacarán, al respecto de la feminización del sector, en el presente estudio ${ }^{8}$.

Ciertamente, a nivel político, la obtención de mayores cotas de igualdad y conciliación sigue siendo un factor prioritario para el Reino de Noruega, ya que existe plena concienciación de que la desigualdad supone un desequilibrio estructural socioeconómico para el país, dado que afecta a

\footnotetext{
2 MIDTTUN, Atle, WITOSZEK, Nina et al. (eds.), The Nordic Model: Is It Sustainable and Exportable? Oslo, University of Oslo, 2011, p. 4.

3 STATISTICK SENTRALBYRÄ. STATISTICS NORWAY, URL: < https://www.ssb.no/en/ > [consultado el 28 de abril 2018].

4 Datos comparativos respecto a España: Tasa de Paro en 2016 de 19,6 (fuente: Instituto Nacional de Estadística); Afiliación Sindical a 2015: 13,09\% (fuente: Trade Union Density, Organisation for Economic Cooperation Development Stat-OECD. Stat); Déficit Presupuestario en 2016 de 4,51\% (fuente: Ministerio de Economía, Industria y Competitividad).

5 ESPINA, Álvaro, «La Sociología del Bienestar de Gösta Esping - Andersen y la reforma del Estado de Bienestar en Europa», in Revista de Libros, 66, 2002, pp. 1-26, URL: < http://ctinobar.webs.ull.es/1docencia/DESIGUALDAD\%20SOCIAL/ESPINA.pdf > [consultado el 28 de abril 2018].

6 MARÍ-KLOSÉ, Pau, MORENO FUENTES, Francisco. J, DEL PINO, Eloísa, «Políticas de género y familia en Noruega y España», in Economía Exterior, 72, 2015, pp. 43-50.

7 Secretary-General's Report to Ministers 2015, OECD, p. 59, URL: < https://www.oecdilibrary.org/docserver/sg_report-2015-

en.pdf?expires=1530471263\&id=id\&accname=guest\&checksum=4505816918E586735E8FA5853DB2EEF4 > [consultado el 28 de abril 2018].

8 BAUM, Thomas, International Perspectives on Women and Work in Hotels, Catering and Tourism. Geneva, International Labour Office, 2013, p. 12.
} 
un elemento tan básico, para su desarrollo, como lo son los recursos humanos. Concepto este, el de la desigualdad, que además va unido inexorablemente al factor de la baja densidad de población; lo que ha llevado a sucesivos Gobiernos noruegos a incentivar la seguridad laboral femenina, en las últimas décadas, obteniendo con ello los resultados buscados, tanto en productividad, como en incremento poblacional. Y al respecto, el «Índice de Fertilidad» (IF) ha ascendido, desde los años setenta, del pasado siglo; superando hoy al español, en cinco décimas, y al de la Unión Europea (UE), casi en tres.

La igualdad tiene un componente moral pero el principal motivo es económico. Una economía moderna y competitiva necesita las mejores cabezas y manos sin mirar de qué raza o sexo son. No podemos permitirnos el lujo de perder los mejores talentos. Y no se trata solo de fijar cuotas, estas deben ir acompañadas de políticas sociales para reconciliar el trabajo y la vida familiar. Tenemos que apoyar a las mujeres; si no, el desafío para alcanzar las posiciones más altas de su profesión será todavía demasiado alto para ellas y los niños no nacerán. Y los niños deben nacer porque son una inversión para el futuro [... $]^{10}$.

El propio pragmatismo político noruego, en aras de la igualdad y conciliación, se ha retroalimentado con la visibilidad y empoderamiento femenino en los diferentes organos de gobieno y representación pública: así, la presencia porcentual de mujeres en el Parlamento actual (Storting) es del 40\%, manteniendo prácticamente igual cifra en los gobiernos municipales ${ }^{11}$. En cuanto al Ejecutivo, el valor alcanzando fue casi del 50\%, para 2016.

Pese a todo, los fundamentos del paradigma social noruego, que es considerado por diferentes estudios la esencia de su fructifera situación actual, a la cabeza del «Índice de Desarrollo Humano» $(\mathrm{IDH})^{12}$, parece arraigar en mayores elementos, que lo que pudiera ser un sentido político práctico de crecimiento y desarrollo ${ }^{13}$. Así, una primera aproximación al comportamiento social de la población noruega muestra una mixtura evolucionada y cohesionada de componentes culturales e ideológicos, que podrían respaldar, en distintos aspectos, la convergencia hacia el actual modelo

\footnotetext{
${ }^{9}$ Datos comparativos en 2016: UE con I. F. de 1,6; Reino de Noruega con 1,77; España con 1,35. Fertility rates by age. Eurostat, 2013, URL: < http://ec.europa.eu/eurostat/statisticsexplained/images/0/0e/Fertility_indicators\%2C_2016.png > [consultado el 28 de abril 2018].

${ }^{10}$ HOLE, Arnie. Directora General de Igualdad, 2011 en Rodríguez, Jesús, «El Manual de la buena vida», in El País. 31 de octubre de 2011, URL: < http://elpais.com/diario/2011/10/30/eps/1319956015_850215.html > [consultado el 29 de abril 2018].

${ }^{11}$ «Proporción de escaños ocupados por mujeres en los parlamentos nacionales», Banco Mundial, URL:

< https://datos.bancomundial.org/indicador/SG.GEN.PARL.ZS?view=chart > [consultado el 29 de abril 2018].

${ }^{12}$ En cambio, paradójicamente, en cuanto al «Índice de Desigualdad de Género»(IDG), Noruega pasa a ocupar el sexto puesto. Informe sobre Desarrollo Humano 2016, Canadá, Programa de las Naciones Unidas para el desarrollo (PNUD), p. 214, URL:

< http://hdr.undp.org/sites/default/files/hdr_2016_report_spanish_web.pdf >[consultado el 29 de abril 2018].

${ }^{13}$ MIDTTUN, Atle, WITOSZEK, Nina et al. (eds), op. cit., p. 6.
} 
social ejemplar; el que contempla, en sí, por otra parte, varios parámetros favorables a la equidad, en diversas áreas sociales.

De esta forma, acudiendo al ámbito laboral, distintos condicionantes morales, que sientan su raiz en la confesionalidad luterana, incidirían en potenciar la «nueva ética frente al trabajo», que implica al total de la población, más allá del género. Y aquí habría que considerar la distancia existente entre la valoración del «carácter sagrado», que Lutero imprimiera a la actividad profesional ${ }^{14}$, frente a la maldición bíblica de «ganarse el pan con el sudor de la frente» ${ }^{15}$, que adoptara el orbe católico; ello por cotejar este aspecto con el caso español, y por ende andaluz, en cuanto que variable comparativa de nuestro estudio.

También se ha señalado otro aspecto importante que, promovido por los diferentes gobiernos noruegos y basado en aspectos pragmáticos de equidad social, además de culturales, cala progresivamente en la sociedad: como lo es la promoción institucional de estructuras «antipatriarcales»; lo cual, sin duda, supone un basamento importante para el logro de una equidad productiva $^{16}$.

En definitiva, en la base de lo que se ha denominado «capitalismo social», aclimatado en los Países Nórdicos, y con especificidades culturales propias para el caso de Noruega, se asientan importantes pilares que favorecerían, entre otras cosas, la consolidación de la igualdad de género, frente a lo que transcurre en el seno del calificado "capitalismo depredador ${ }^{17}$, instalado en la Europa Continental y Atlántica, y que parece avanzar a la fagocitación de las cotas de equidad recién alcanzadas.

\section{La Industria Turística Rural en Noruega y Andalucía: estado de la} cuestión

Adentrarse en el desarrollo y evolución de la Industria del Turismo hoy es también aproximarse a sus primitivos orígenes, en cuanto que receptora y generadora de aquel primitivo

\footnotetext{
${ }^{14}$ URIBE Garcés, LUCÍA, Olga «El Trabajo asalariado: La mecanización del espíritu», en AD-MINISTER Universidad EAFIT, 12, 2008, p. 124, URL:

< http://publicaciones.eafit.edu.co/index.php/administer/article/view/558 > [consultado el 30 de abril 2018].

${ }^{15}$ Génesis 3, 19. Biblia, URL : < https://www.lds.org/scriptures/ot/gen/3?lang=spa > [consultado el 28 de abril 2018].

${ }^{16}$ TRÄGÅRDH, Lars, Social Trust and Radical Individualism, in MIDTTUN, Atle, WITOSZEK, Nina, et al. (eds.), The Nordic Model: Is it Sustainable and Exportable?, Oslo, University of Oslo, 2011, pp. 18-19, URL:

$<$ http://www.forskningsradet.no/en/Newsarticle/The_Nordic_social_model_Sustainable_prosperity_and_ welfare $/ 1253964904388 \& p=>$ [consultado el 30 de abril 2018].

${ }^{17}$ BECK, Ulrich, «Indignados entre el poder y la legitimidad. Una alianza entre los movimientos globales de protesta y la política de los Estados nacionales podría conseguir que no fuera la economía la que dominase la democracia, sino la democracia a la economía», in El País, 10 noviembre 2011, URL:

<https://elpais.com/diario/2011/11/10/opinion/1320879611_850215.html> [consultado el 30 de abril 2018].
} 
entusiasmo "explorador», que invadiera a la sociedad europea, en los comienzos de la Contemporaneidad; lo que pronto iría acompañado del nuevo concepto social de «tiempo libre», ante los cambios de hábitos introducidos por la naciente sociedad burguesa ${ }^{18}$; favoreciendo así, aún más, la expansión de la práctica viajera ${ }^{19}$.

Un aspecto destacado, en cuanto a la manifestación temprana de la profesionalización e industrialización del turismo noruego, es la precoz aparición del asociacionismo en torno a la temática: en 1903 se constata la primera agrupación al respecto, la «Asociación de Turismo y Viaje de Noruega» - «Foreningen for Reiseliv i Norge» - , que nacería con la pretensión de establecer la colaboración gubernamental con el sector privado, para el desarrollo de la actividad turística, en tanto que fuente de ingresos para el crecimiento. Y, concretamente, según se ha estudiado, el actual Consejo Turístico de Noruega - «Norges Turistråd» - tiene sus orígenes en esta primera célula asociativa ${ }^{20}$.

Con tan madrugadores inicios, la Industria Turística en Noruega, un sector que representó en 2012 el 3,3\% del PIB, dando empleo al 6,3\% de la población ${ }^{21}$, siendo el 60,2\% femenina, para $2008^{22}$, continúa creciendo, aunque de forma más ralentizada, según estudios institucionales para el ramo.

Respecto a España, es cierto que para el sector las cifras se triplican: en cuanto al Turismo Rural, desde los años 50, se seguiría los modelos centroeuropeos de expansión y desarrollo. Por más, ciñéndonos a Andalucía, y en exclusiva al segmento de Turismo Rural, siendo que su población en municipios propiamente rurales representa un 54,9\%, y pese a su extensión, así como a la diversidad de rasgos y accidentes geográficos, su oferta se sitúa aún por debajo de la media nacional, aun suponiendo la Agricultura y el Turismo sus principales impulsos de crecimiento $^{23}$. Y habiendo crecido la oferta rural, durante la última década, también parece ralentizarse su productividad, al igual que para el caso noruego ${ }^{24}$. Al respecto, resultan muy ilustrativos estudios comparativos realizados en otras regiones del planeta, de similares

\footnotetext{
${ }^{18}$ PRIEGO DE MONTIANO, Gloria, Orígenes del Asociacionismo Cordobés Contemporáneo. Tipología asociativa en la Córdoba del XIX (1779-1900), Córdoba, Servicio de Publicaciones de la Universidad de Córdoba-Diputación de Córdoba, 2011, pp. 151-152.

${ }^{19}$ CORBIN, Alain, L'Avenement des Loisirs 1850-1960, Paris, Aubier, 1995, pp. 335-340.

${ }^{20}$ NORDB $\varnothing$, Ingeborg, Living with tourism. The Case of small-scale rural tourism business in Norway and Chile, Aalborg University, SPIRIT \& Department of Culture and Global Studies, 2009. pp. 8-9, URL: $<$ http://vbn.aau.dk/en/publications/living-with-tourism-the-case-of-smallscale-rural-tourism-business-innorway-and-chile(563b7bb0-a103-493f-9175-0788fa066861).html> [consultado el 29 de abril 2018].

${ }^{21}$ OFICINA ECONÓMICA Y COMERCIAL DE LA EMBAJADA DE ESPAÑA EN OSLO, Estructura Económica de Noruega, Oslo, Instituto Español del Comercio Exterior-ICEX, 2012, p. 8.

${ }^{22}$ BAUM, Thomas, op. cit., p. 39. Considérese la cifra de referencia, salvando la horquilla temporal, dado que hasta 2012 no entró en vigor la reglamentación europea a cerca de facilitar datos estadísticos comparativos y periódicos sobre la actividad turística del consorcio.

${ }^{23}$ «El Turismo Rural en Andalucía», in Observatorio del Turismo Rural, 2014, URL:

< http://www.escapadarural.com/observatorio/turismo-rural-andaluz-2014/ > [consultado el 2 de mayo 2018].

${ }^{24}$ INSTITUTO DE TURISMO DE ESPAÑA Plan Integral de Turismo Rural, Madrid, 2014, pp. 4-5, 27.
} 
características orográficas y demográficas, que han establecido patrones de análisis indicativos, para la evaluación de este tipo de actividad y su problemática ${ }^{25}$. En cuanto al PIB que aporta la Industria Turística a la Comunidad Andaluza, éste es del $13 \%{ }^{26}$; manteniendo una ocupación laboral del 37\%, para $2015^{27}$.

Tratando de buscar condicionantes de la citada aminoración de crecimiento de la Industria Turística, para los casos comparados, y siendo, ésta, una industria considerada en la actualidad como efectivo y eficiente motor de crecimiento, además de catalizador de otros muchos sectores, así como potencial de mayores transformaciones competitivas ${ }^{28}$, habría que acudir al seguimiento de las diferentes líneas estructurales establecidas, tanto en Noruega, como en la Comunidad Autónoma de Andalucía, para conocer a fondo la progresión turística rural, que nos ocupa. Acotando, así, precisamente, un periodo de interesante rastreo, por coincidir con las medidas políticas más recientes; las que perseguirían un intento de encauzar las acciones gubernamentales hacia una nueva modernización, en busca de una readaptación al actual mercado, con ánimo de elevar el crecimiento.

De forma que así, durante las décadas 80 y 90, se puede constatar que el Gobierno noruego, concienciado de la importancia del sector, despliega programas de estudio y expansión: «Sobre Turismo y Viaje» («Om reiseliv»); patronazgo y desarrollo, «Regulación de la Industria de Viajes» («Sats på reiselivet»); productividad y beneficio, «Industria del Turismo Rentable y Competitivo» («Lønnsomme og konkurransedyktige reiselivsnæringer»); hasta llegar al 2005, con una nueva planificación, que se vería reforzada, pasados dos años, por mayores medidas institucionales, como la «Declaración de Soria Moria» («Soria Moria- erklaeringen») ${ }^{29}$.

\footnotetext{
${ }^{25}$ FUENZALIDA DÍAZ, Manuel, FIGUEROA STERQUEL, Rodrigo, NEGRETE SEPÚLVEDA, Jorge «Evaluación de la aptitud territorial para el turismo de naturaleza y rural Reserva de la Biosfera La Campana-Lago Peñuelas, Chile», in Estudios y perspectivas en turismo, 22, 2013, pp. 120-137, URL:

$<$ http://www.scielo.org.ar/scielo.php?script=sci_arttext\&pid=S1851-17322013000100007\&lng=es\&tlng=es > [consultado el 2 de mayo 2018].

${ }^{26}$ PORTAL DE LA JUNTA DE ANDALUCÍA. TURISMO Y DEPORTE, URL:

< http://www.juntadeandalucia.es/andalucia/economia/turismo.html > [consultado el 2 de mayo 2018].

${ }^{27}$ CONSEJERÍA DE TURISMO Y DEPORTE, Empleo del Sector Turístico en Andalucía. Año 2015, Sevilla, 2015, p. 17, URL: < http://www.juntadeandalucia.es/turismoydeporte/publicaciones/estadisticas/empleo_2015.pdf > [consultado el 2 de mayo 2018].

${ }^{28}$ Los estudios económicos sitúan al Turismo, para el 2020, en el 11,3\% del PIB mundial, proporcionando trabajo al 8,3\% de la población. CÁRDENA GARCÍA, Pablo J., PULIDO FERNÁNDEZ, Juan I., SÁNCHEZ RIVERO, Marcelino, «El crecimiento turístico como determinante del desarrollo económico en los países pobres. Un análisis multivariante», URL:

<http://www.aecit.org/uploads/public/congresos/16/Comunicaciones/Sesion\%201/5.\%20Crecimiento\%20t uristico\%20como\%20un\%20determinante\%20del\%20desarrollo\%20economico.pdf > [consultado el 2 de mayo 2018].

${ }^{29}$ XIANG YING, Mei, ARCODIA, Charles, RUHANEN, Lisa, «A National Government's Tourism Innovation Initiatives: A Review of Tourism Development Policies in Norway", in Tourism: Creating and brilliant blend, National Conference, 2011, pp. 5 et seq., URL:

< http://espace.library.uq.edu.au/view/UQ:239384/UQ239384_fulltext.pdf > [consultado el 2 de mayo 2018].
} 
A lo largo de algo más de tres décadas, pues, se han ido estableciendo las bases de una industria moderna y en crecimiento, a través del desarrollo de estrategias de promoción del turismo de naturaleza y cultural y ecológico y rural; una financiación y difusión internacional de los productos; el refuerzo de la calidad; la búsqueda de confianza del mercado; el implemento de la formación y preparación, así como la creación de una marca nacional propia. A todo lo que se ha ido sumando también una insistente política de medidas de innovación, creación de redes, aplicación de nuevas tecnologías, sostenibilidad y establecimiento de medidas diferenciales, de fortalecimiento local y regional o «Robuts Regions» ${ }^{30}$.

No obstante, pese a tan sistemáticas acciones adoptadas por el Gobierno noruego, para la regulación de la industria turística, en aras de su crecimiento, diferentes análisis especializados inciden en escrutar las causas del lento avance, frente al potencial desplegado por el sector público y empresarial. De tal manera, y partiendo de unos valores de medición sobre beneficios potenciales, que llevarían a establecer resultados de «competitividad turística» alta, media o baja, y siendo que Noruega ha contemplado la mayoría de estos indicadores, en sus políticas de implementación, el balance de resultados la sitúan, sin embargo, en un «crecimiento subeslástico»; esto es, por debajo de sus posibilidades de desarrollo, frente a su caudal efectivo y recursos invertidos ${ }^{31}$. Por otro lado, se argumenta que las medidas de innovación y desarrollo turístico llevadas a cabo no resultan tan novedosas, además de considerar que el Estado muestra cierta posición de pasividad en su aplicación, recayendo la responsabilidad finalmente en el empresariado implicado ${ }^{32}$.

Por lo que respecta a la tesis que abundan en señalar cierta pasividad gubernamental, hay que considerar que los procedimientos institucionales desplegados no parecen indicar que se traslade la responsabilidad de aplicación de las políticas trazadas al empresariado, dado que se encuentran partidas de fondos liberados anualmente, por parte de los distintos Ministerios implicados, así como diversos programas y proyectos institucionales de impulso al fomento de colaboración pública y privada, encaminados al desarrollo de la industria turística ${ }^{33}$. También coinciden otras

\footnotetext{
${ }^{30}$ Cfr. NORWEGIAN MINISTRY OF LOCAL GOVERNMENT AND REGIONAL DEVELOPMENT, Regarding Rural and Regional Development Policy, s.l., Kjersti Bjego 2001; NORWEGIAN MINISTRY OF LOCAL GOVERNMENT AND REGIONAL DEVELOPMENT On Rural and Regional Policy., s.l., Norwegian Ministry of Local Government and Regional Development, 2013; INNOVATION NORWAY, Annual Report. Innovation Noway 2014, Oslo, Innovation Norway, 2014.

${ }^{31}$ PULIDO FERNÁNDEZ, Juan Ignacio, SÁNCHEZ RIVERO, Marcelino, «Competitividad versus crecimiento en destinos turísticos. Un análisis mediante técnicas multivariantes», in Cuadernos de Economía, 33, 91, 2010, pp. 5-208, esp. p. 171.

${ }^{32}$ XIANG YING, Mei, ARCODIA, Charles, RUHANEN, Lisa, op. cit., pp. 8-9.

${ }^{33}$ NORDB $\varnothing$, Ingeborg, Living with tourism. The Case of small-scale rural tourism business in Norway and Chile, Tesis doctoral - Aalborg University, 2009, 169-223. Vid. etiam. NORWEGIAN MINISTRY OF TRADE AND INDUSTRY, Valuable Experiences. National Strategy for the Tourism Industry, s.l., Norwegian Ministry of Trade and Industry 2007, pp. 18-24; NORWEGIAN MINISTRY OF LOCAL GOVERNMENT AND REGIONAL DEVELOPMENT, On Rural and Regional Policy, s.l., Norwegian Ministry of Local Government and Regional Development, 2013, pp. 7-9.
} 
investigaciones, al respecto, en que es necesario ampliar el campo de estudio, para aportar mayores resultados sobre la cuestión ${ }^{34}$.

Llegando a este punto, resulta esencial enfocar el asunto hacia nuevos agentes implicados, que aporten diferentes variables a la ya expuestas. Así, pese a la coordinación ministerial, se ha insistido en la demanda de un ministerio especializado en el ramo ${ }^{35}$. Por otro lado, acudiendo al análisis realizado por la Cámara de Comercio noruega, en los años de máxima incidencia de la renovada política de fomento turístico, se apuntó a la excesiva fragmentación del sector y la baja profesionalización, como rémoras al crecimiento; aportado la idea del desarrollo de mayor asociacionismo, entre una de las posibles alternativas.

Existen también estudios que coinciden en señalar la excesiva estructura familiar en el sector turístico, «microturismo», como elemento ralentizador de crecimiento ${ }^{36}$. Al respecto, dichos trabajos, igualmente destacan la amplia feminización del sector, así como la presencia de un alto porcentaje de mujeres al frente de las empresas, si bien la «brecha salarial» aún se acentúa, dado el tamaño de los negocios.

Enfocando hacía la Comunidad Andaluza, también hacia los años 80 y 90, coincidiendo con el propio despliegue institucional en tanto que «Comunidad Autónoma de Andalucía» del Estado Español, se desarrollaría la implantación de toda la infraestructura normativa, que enmarcaría a las distintas actividades englobadas en el concepto de Turismo Rural; muchas de ellas, al calor de diversas regulaciones europeas ${ }^{37}$. Implantado, así, el marco normativo básico, se desplegarían las distintas líneas y políticas de actuación, sustentado todo ello, fundamentalmente, en una red asociativa, que abarcaría a los distintos sectores y agentes sociales, empresariales e institucionales implicados.

Los objetivos trazados se encaminarían a la recuperación y renovación de viviendas, al intento de recuperación poblacional, tras décadas de éxodo urbano; al implemento de la economía autóctona, complementando la tradicional agrícola y ganadera con la del turismo rural, siguiendo con ello las nuevas tendencias de reconversión ${ }^{38}$; a la creación de empleo, la formación específica

\footnotetext{
${ }^{34}$ RøNNINGEN, Martin, «Innovation in the Norwegian Rural Turism Industry: Results from a Norwegian Survey», in The Open Social Science Journal, 3/2010, pp. 15-29, pp. 15-16.

${ }^{35}$ Son varios los ministerios implicados en el sustento y financiación de la industria turística noruega, de forma directa o indirecta: Comercio e Industria (Næringsministeren); Agricultura y Alimentación (Landbruks- og matministeren); Administración Local y Modernización (Kommunal- og moderniseringsministeren) Clima y Medioambiente (Klima- og miljøministeren); Educación e Investigación (Kunnskapsminister); Pesca (Fiskeriministeren); Cultura (Kulturministeren); Transporte y Comunicaciones (Samferdselsminister) y Asuntos Exteriores (Utenriksminister).

${ }^{36}$ NORDBØ, Ingeborg, op. cit., pp. 99-102; HJALAGER, Anne-Mette «Repairing innovation Defectivinees in turism», in Turism Management, 23, 5/2002, pp. 465-474.

${ }^{37}$ RODRÍGUEZ GARCÍA, Luis, OSUNA RODRÍGUEZ, Mercedes (coord.), MUJERES, turismo rural y brecha salarial de género: una propuesta de investigación, acciones de fomento y sensibilización, Córdoba, UCOPress, Editorial Universidad de Córdoba, 2015, pp. 136-137.

${ }^{38}$ BLEKESAUNE, Arild, BRANDTH, BERIT \& HAUGEN, Marit S., «Visiting a farm based tourist enterprise. Who
} 
para el sector y, en fin, a toda acción que corrigiera los desequilibrios estructurales que se venían produciendo, desde los setenta, entre los ámbitos rural y urbano andaluces ${ }^{39}$.

En el balance de resultados andaluz, transcurridas tres décadas de intensa planificación para el desarrollo del Turismo Rural, se observan coincidencias con algunos los factores de ralentización detectados para el caso noruego, tras el mismo periodo de ejecución de diversas medidas de implementación; pese a que el sector andaluz, presenta diferente perfil, en cuanto al contexto geográfico, socioeconómico y cultural. Así, para ambas muestras se constata un sector atomizado de microempresas, de carácter unifamiliar, sin consolidada conexión comercial con la producción agroalimentaria y/o la producción tradicional del núcleo rural. Por lo demás, igualmente feminizado y mayormente asociado al ámbito de la economía doméstica ${ }^{40}$.

\section{El Turismo Rural como potencial en desarrollo}

El Turismo Rural noruego, en tanto que inmerso en el capítulo de la Industria Turística general, ha venido siendo objeto de las distintas medidas políticas de impulso al crecimiento, desde hace algo más de tres décadas, como ya se ha expuesto. Suscitando, además, una específica y concreta atención, dada su importancia para la cohesión regional de todo el país, en un intento de frenar el continuo descenso de población rural. Y ello considerando la escasez demográfica, en las zonas rurales de Noruega, que representa tan solo algo más del $20 \%$, frente a la urbana: y las últimas mediciones arrojan un nuevo descenso, en la horquilla de 2013 a 2014, con una pérdida de densidad del $0,2 \%{ }^{41}$.

El éxodo de población, fundamentalmente joven, y de forma especial femenina ${ }^{42}$, se ha venido constatando, desde las décadas 80 y 90, del pasado siglo, en estrecha relación con la falta de oferta

are the visitors and what is the future potential?», in Paper to the 17th Nordic Symposium in Tourism and Hospitality Researchp, p. 3. URL: < https://ruralis.no/wp-content/uploads/2017/05/14940f8dde7671-1.pdf > [consultado el 4 de mayo 2018]. Vid. etiam. MORA MÉNDEZ, Franklin M., CHIRIBOGA CISNEROS, Edison Fernando, «Turismo Agroecológico: Alternativa de Desarrollo Turístico Sostenible en la Zona Rural de la Provincia del Guayas», in INNOVA Research Journal, 2, 5/2017, pp. 152-162, esp. p. 157.

${ }^{39}$ Recuérdese que en Andalucía el 54,92\% de su población se asienta en núcleos rurales. Vid. supra. Núcleos, estos, de producción mayoritariamente agrícola-ganadera. Con un importante indicador para el desarrollo de la actividad turística: grandes oscilaciones, en cuanto a la densidad poblacional, entre las zonas costeras, de mayor desarrollo y las sierras e interior. La Población Andaluza. Andalucía Estadística y Geográfica, Instituto de Estadística y Cartografía de Andalucía. Consejería de Economía, Innovación y Ciencia, 2011, p. 7. URL: <https://www.juntadeandalucia.es/institutodeestadisticaycartografia/estadisticaygeografica/1_PoblacionA ndaluza.pdf > [consultado el 4 de mayo 2018].

${ }^{40}$ CONSEJERÍA DE TURISMO Y DEPORTE, Andalucía. Empleo del Sector Turístico en Andalucía. Año 2015. Economía del Turismo en Andalucía, Sevilla, Consejería de Turismo y Deporte, 2015, pp. 11-12; RODRÍGUEZ GARCÍA, Luis, OSUNA RODRÍGUEZ, Mercedes el al., op. cit., pp. 144-150; NORDBØ, Ingeborg, op. cit., p. 89-97.

${ }^{41}$ Statisisk Sentralbyrä. Statistick Norway, National Statistical Institute of Norway, URL: < https://www.ssb.no/en/befolkning/nokkeltall/population >[consultado el 4 de mayo 2018].

${ }^{42}$ HAUGEN, Marit S, VILLA, Mariann, Rural Idylls or Boring Places?, in BOCK, Betina B., SHORTALL, Sally (eds.), Rural Gender Relations: Issues and Case Studies, Oxfordshide, CABI Publishing, 2006, pp. 181-195, p. 182. 
laboral, formativa y lúdica, en estas áreas. Desplazando, así, el «centro de gravedad» poblacional noruego hacia las ciudades, lo que preocupa a las autoridades, de cara a la estabilidad del sistema de bienestar nacional logrado. Y al respecto, desde el año 2000 se vienen sucediendo medidas institucionales específicas, para invertir la tendencia: las que pasan por el desarrollo del empleo y la vivienda; la extensión de mayores servicios públicos; la cooperación entre organismos oficiales y empresas privadas, para la creación de nuevos nichos de negocio, en estos territorios; la formación e innovación; la financiación pública, y otras. Además, se insiste en poner el acento en la adopción de políticas de igualdad de género, con objeto de mejorar así las condiciones generales de vida y el crecimiento demográfico: «finding a healthy environment for children is an important reason for settling away from the cities» ${ }^{43}$. Persistiendo, a la par, en dirigir esfuerzos al fomento de la participación de mujeres y jóvenes, en el crecimiento y revitalización de las zonas rurales, a través de la formación de nuevas empresas ${ }^{44}$.

Posteriores actuaciones institucionales han incidido en estas medidas, poniendo también el acento en la creación de redes, en las temáticas medioambientales y la sostenibilidad, así como reiterando igualmente la importancia de las políticas de género y la creación y el fortalecimiento de la pequeña y mediana empresa; para todo lo que se acentúa también, en todo momento, la importancia del papel impulsor familiar femenino ${ }^{45}$.

La mayoría de las disposiciones, adoptadas a lo largo de estos años, por el Gobierno noruego, convergen ampliamente con las grandes líneas de ejecución trazadas por la Unión Europea, de cara a mantener y reforzar el «capital territorial» de las regiones rurales de Europa ${ }^{46}$. Por otro lado, la efectividad de las líneas institucionales trazadas viene siendo objeto, de igual modo, de diversos trabajos de investigación, en valoración cualitativa y cuantitativa, in situ ${ }^{47}$.

\footnotetext{
${ }^{43}$ Report $n^{\circ} 34$ (2000-2001) Ministry of Local Government and Regional Development, s.l., Kjersti Bjego, p. 9. URL: < https://www.regjeringen.no/no/dokumenter/report-no-34-2000-2001/id516357/ > [consultado el 4 de mayo 2018].

${ }^{44}$ ANGELL, Elisabeth, FLO, Yngve, GRINSRUD, Gro Marit, The Rural and Regional Policy of Norway Instiutions, Development Features and Current Instruments, Bergen, Stein Rokkan Centre for Social Studies, 2016, p. 61. Si bien las disposiciones institucionales para activar la economía rural se documentan desde los años noventa, para este trabajo, determinadas entidades venían organizando iniciativas ya desde los sesenta, en distintas zonas de la geografía noruega. Cfr. AARTUN, Karl. «Norden», el periódico más nórdico», in Boletín Informativo. Servicio de Extensión Agrícola, 42, 1961 pp. 24-26, URL:

<http://www.magrama.gob.es/ministerio/pags/biblioteca/revistas/pdf_BEA\%5CBEA_1961_42.pdf [consultado el 4 de mayo 2018].

${ }^{45}$ NORWEGIAN MINISTRY OF TRADE AND INDUSTRY, op. cit., 46 et seq.; INNOVATION NORWAY, op. cit, p. 34.

${ }^{46}$ Agenda Territorial de la Unión Europea 2020. Hacia una Europa integradora, inteligente y sostenible de regiones diversas, Gödölö, Hungria, 2011, pp. 4 et seq. URL:

<http://www.mapama.gob.es/es/desarrollo-rural/planes-y-estrategias/desarrollo-territorial/el-desarrolloterritorial-en-el-ambito-europeo/union-europea/ > [consultado el 4 de mayo 2018].

${ }^{47}$ NYBAKK, Erlend, VENNESLAND, Birger, HANSEN, Eric, LUNNAN, Anders, «Networking, Innovation, and Performance in Norwegian Nature-Based Tourism», in Journal of Forest Products Business Research, 5, 2008, p. 8. URL:

<https://www.researchgate.net/publication/241688479_Networking_innovation_and_performance_in_Nor wegian_nature-based_tourism $>$ [consultado el 5 de mayo 2018]. NYBAKK, Erlend, HANSEN, Eric,
} 
Por lo demás, escrutar las distintas manifestaciones de turismo rural que coexisten actualmente en Noruega se presenta harto complejo, dada la diversidad y mixtura de la tipología de este tejido empresarial; algo, por otra parte, que también ocurre en otros muchos países y regiones del entorno europeo, para esta rama de la actividad turística, como es el caso igualmente para Andalucía.

De otro lado, a la dificultad que aporta esta disparidad de tipologías de negocio, para su análisis y estructuración, se añade el alto componente socioeconómico y cultural que presentan, normalmente, en su origen, este perfil de empresa, por lo que se requiere un mayor conocimiento de las bases sociales y culturales que influyeron en sus inicios, de cara a profundizar en su estudio. Siendo así, analizar además los distintos datos con perspectiva de género, dado el acento que se pone en la funcionalidad del papel de las mujeres, tal que eje vertebrador del cambio, desde las distintas instituciones noruegas, españolas y andaluzas, incluyendo también a la propia Comisión Europea; cuando no existen cifras desagregadas en multitud de balances, series estadísticas, informes, estudios y otros documentos exploratorios, agrega más complicación a la tarea.

Pese a ello, intentando una aproximación al objetivo perseguido, entre algunas de las consecuencias a extraer se encuentran las diferencias constatadas, dependiendo del modelo de negocio rural de que se trate: bien sea «agroturismo» (farm; forest) ${ }^{48}$ o bien la amplia gama hospedajes que se presentan en esta categoría turística ${ }^{49}$. Por otro lado, dándose mayor representación de pequeñas y medianas empresas, para el caso del agroturismo, tratándose, así, la mayoría de las veces, de negocios familiares ${ }^{50}$, ello dista bastante del patrón de actuación seguido por el grupo general del Turismo Rural de alojamiento. Del que, por otra parte, es difícil obtener datos independientes, ya que la mayoría de ellos se presentan agrupados a otros ramales globales de la hostelería y restauración, lo que complica un tanto la obtención de resultados precisos.

En cuanto a la proporcionalidad de dedicación de hombres y mujeres al agroturismo en la actualidad $^{51}$, en lo que respecta a las muestras de análisis, cifras que se han ido equiparando

«Entrepeneurial attitud innovation and performance among Norwegian nature-based turism enterprises», in Forest Policy and Economics, 10, 2008, pp. 475-478.

${ }^{48}$ Ya en 2008 se contabilizó que el 10\% de las empresas agrícolas noruegas se dedicaban también a la nueva fórmula de turismo rural, pues el mero alojamiento en estos recintos tiene raíces tradicionales anteriores. BLEKESAUNE, Arild, BRANDTH, Berit, HAUGEN, Marit S., op. cit., pp. 6-7.

${ }^{49}$ BAUM, Thomas, International Perspectives on Women and Work in Hotels, Catering and Tourism, Geneva, International Labour Office, 2013, pp. 6-8. URL:

<http://www.ilo.org/gender/Informationresources/WCMS_209867/lang--en/index.htm > [consultado el 5 de mayo 2018].

${ }^{50}$ GURRÍA Di-BELLA, Manuel, El Turismo Rural Sostenible como una oportunidad de desarrollo de las pequeñas comunidades de los países en desarrollo, 2000, URL: < http://kiskeya-alternative.org/publica/diversos/ruraltur-gurria.html $>$ [consultado el 5 de mayo 2018].

${ }^{51}$ BJØRKHAUG, Hilde, TURID KVAM, Gunn, «Local small-scale food enterprises: ambitions and initiatives for achieving business growth among male and female owners and managers", in Ager. Revista de Estudios sobre Despoblación y Desarrollo Rural, 11, 2011, pp. 35-51, URL: <http://www.ceddar.org/ager-revista-estudiosdespoblaci\%C3\%B3n-desarrollo-rural_publicacion_en_339.html > [consultado el 5 de mayo 2018]. 
progresivamente; ello es, en gran parte, resultado de las políticas seguidas desde los años noventa, cuando comenzó lo que se ha dado en llamar discriminación positiva o "gender-wise», que favorecería, para el caso noruego, en un 75\%, a mujeres y jóvenes, para la creación de nuevas empresas. Una década más adelante se insistiría en una mayor facilidad de concesión de préstamos, en la misma línea; llegándose, así, en 2005, al 50\% de presencia femenina en el sector. A continuación, ya en 2008, se presentaría un plan de acción que declararía abiertamente buscar que las mujeres ocuparan la presidencia de dichos negocios, en un 40\%. También en Andalucía se han venido llevando a cabo una serie de medidas institucionales, en este mismo sentido de equiparación igualitaria en el sector, desde las mismas fechas, por parte de la Junta de Andalucía o gobierno autonómico regional ${ }^{52}$.

Promover la igualdad entre hombres y mujeres en el mundo rural es fundamental para reconocer la potencialidad que las mujeres rurales pueden ejercer en la vertebración de dicho territorio [...] es necesario dar el valor que merece al papel de las mujeres rurales en la construcción del nuevo modelo de sociedad rural y en la nueva política agraria común [...]53.

Pese a todo el despliegue institucional desarrollado por parte de ambos gobiernos, estudios especializados posteriores concluyen que los objetivos alcanzados distan aún del montante planificado. No obstante, algunas mediciones de 2011 sitúan por encima del 50\% el porcentaje femenino al frente de la dirección de los negocios de agroturismo, en Noruega ${ }^{54}$. Si bien, hay que señalar que otras investigaciones ya apuntaron, anteriormente, que gran número de estas empresas, aunque son regidas de facto por mujeres, "tradicionalmente» están registradas, sin embargo, a nombre de sus maridos ${ }^{55}$. Lo que también se ha detectado para la Comunidades de Andalucía, en España, donde en un 70\% constan las mujeres al frente de la empresa rural, mientras la titularidad nominal es masculina ${ }^{56}$.

En relación a los datos arrojados por la Organización Internacional del Trabajo (OIT), para el apartado de «Hoteles, Catering y Turismo», donde se incluyen también los resultados internacionales de Turismo Rural, las últimas cifras de dedicación femenina constatadas para Noruega son de un 66,2\%; porcentaje que aumenta para la franja de edades inferiores a veinticuatro años. En cuanto al recogido para el conjunto del Estado Español, éste se sitúa en el 59,9 , para las mismas fechas ${ }^{57}$. Sin embargo, los recuentos desagregados por género, para los puestos de dirección, no se muestran en los resultados de los estudios analizados, sino de forma

\footnotetext{
${ }^{52}$ RODRÍGUEZ GARCÍA, Luis, OSUNA RODRÍGUEZ, Mercedes el al., op. cit., pp. 149-150.

${ }^{53}$ Ibidem, p. 142.

${ }^{54}$ BJØRKHAUG, Hilde, TURID KVAM, Gunn, op. cit., p. 39.

${ }^{55}$ NORDB $\varnothing$, Ingeborg, op. cit., p. 97

${ }^{56}$ RODRÍGUEZ GARCÍA, Luis, OSUNA RODRÍGUEZ, Mercedes el al., op. cit., p. 82.

${ }^{57}$ BAUM, Thomas, op. cit., p. 41.
} 
parcelada. Tampoco se encuentran concreciones en la información procedente de organismos específicos; y todo debido a la amplia variedad de formatos de negocio que presenta la modalidad de hospedaje escrutada, además de otros factores de solapamiento de las funciones realizadas por la población femenina ${ }^{58}$.

Abundando en lo que respecta a las diferencias salariales, por razones de género, el carácter de «proyecto familiar», de la mayoría de este tipo de empresas, hace complejo el establecer conclusiones rigurosas, ya que las más de las veces no se establecen asignaciones concretas de tareas, entre las personas al frente de la dirección u otros cargos; más bien se intersolapan funciones y labores ${ }^{59}$, por lo que para hallar distinciones hay que acudir al análisis de otros factores diferenciales, como algunos de los que se están apuntando. Incluso, algunos estudios han señalado precisamente la «invisibilidad», en ocasiones, del trabajo femenino desarrollado en estas empresas familiares, ya que se llega a asimilar a una "asistencia», más próxima a la labor doméstica; alejada, por tanto, del carácter profesional que sí se imprime al llevado a cabo por el personal masculino ${ }^{60}$.

Por lo demás, incursiones a través de ciertos patrones conductuales avanzan nuevos datos para la continuación de la investigación del ramo. Y así es respecto a la mayor permanencia de roles de género en los negocios noruegos de agroturismo, frente a los de hospedaje rural genérico: de esta forma, entre el empresariado femenino dedicado al agroturismo se constata mayor tendencia a establecerse familiarmente en el lugar de arraigo del negocio, por encima del 60\%; mientras que en el grupo masculino la incidencia se sitúa en el 30\%. También se encuentren disimilitudes en lo que respecta a la cualificación de titulares al frente del negocio, siendo que las empresarias presentan mayor tasa de estudios universitarios; contrariamente a la prevalencia, entre el personal masculino, de un nivel medio de especialización profesional ${ }^{61}$.

Volviendo a la Comunidad Andaluza, y continuando con los parámetros marcados por la Unión Europea $^{62}$, así como por la Ley para el Desarrollo Sostenible del Medio Rural 45/2007, de 13 de diciembre, se encuentran nuevas líneas de actuación, para la reestructuración y potenciación de las diferentes vertientes del Turismo Rural. Coincidiendo, varias de ellas, con algunos planteamientos también llevados a cabo en el país nórdico, basados en diagnósticos socioeconómicos propios de aquella comunidad, tan distante de la andaluza. Así, se encuentran

\footnotetext{
$5^{8}$ TORNS, Teresa, RECIO CÁCERES, Carolina, «Las desigualdades de género en el mercado de trabajo: entre la continuidad y la transformación», in Revista de Economía Crítica, 14, 2012, pp. 178-202, p. 187.

59 «[...] one can often observe situations in which the owner-managers may be chef, caretaker, gardener, host, switchboard operator and cleaner all in one day». NORDBØ, Ingeborg, op. cit., p. 183; «[...] a central characteristic might be the involvement of family members in voluntary, unpaid, or unwaged employment». Ibidem, p. 89.

${ }^{60}$ SHORTALL, Sally, Gender and Farming: An Owerview, in ID. (ed.), Rural Gender Relations: Issues and Case Studies, cit., pp. 21-30.

${ }^{61}$ BJøRKHAUG, Hilde, TURID KVAM, Gunn, op. cit., p. 39.

${ }^{62}$ RODRÍGUEZ GARCÍA, Luis, OSUNA RODRÍGUEZ, Mercedes el al., op. cit., pp. 89-100.
} 
disposiciones dirigidas a la equidad de género en el ámbito rural buscando la repoblación, dado el endémico envejecimiento poblacional. En dicho marco, se adoptan medidas potenciadoras del empleo femenino; favorecedoras de la creación de un tejido asociativo de mujeres, en tanto que catalizador de mayor dinamismo social, como se ha indicado, así como el apoyo a la iniciativa empresarial femenina. También, una mayor extensión de formación emprendedora, para el conjunto de la población. Al igual que se viera en el caso noruego, se pretende insistentemente una mayor participación e imbricación de agentes sociales, económicos e institucionales ${ }^{63}$. Además, las coincidencias se encuentran igualmente en la apuesta decidida por la innovación, la creación de redes y el cuidado y la valoración medioambiental. Del mismo modo, en establecer una sólida interconexión entre lo rural y lo urbano, como base para fortalecer la estructura de la economía del medio rural, más allá de la actividad meramente hotelera y asistencial que, como es sabido, conlleva un fuerte componente estacional.

\section{A modo de balance}

Partiendo del cotejo de las dos variables comparativas establecidas, en torno al desarrollo de la industria turística rural en Europa: Andalucía y Noruega; lo que en un principio podría parecer aleatorio, se pretende el inicio de una línea de estudio, en la que se analice el resultado de las políticas aplicadas en el marco europeo, en las cuatro últimas décadas, referidas al sector; considerando, a su vez, los condicionantes humanos, geográficos, culturales, empresariales, laborales y otros de diversa clasificación, que intervienen en el proceso. El periodo temporal elegido es significativo, en tanto que se corresponde con una coyuntura de cambio importante para las regiones objeto de estudio: para Noruega supondría el momento pleno del usufructo de la explotación petrolera, fuente de ingresos fundamental para el presupuesto nacional $-16,9 \%$ del PIB, en 2016, según últimos datos de la Oficina Comercial de España en Oslo-64; para Andalucía, el comienzo de su andadura como región con gobierno autónomo, dentro del Estado de España, además de otra serie novedades económicas y político-administrativas, derivadas del final del periodo franquista. Añadido a esto, se da la circunstancia de que es entonces cuando se empieza a contemplar el Turismo Rural como fuente importante de ingresos, por parte de los estados, y por tanto desarrollo, así como de ocupación. A ello se une que los inicios del momento de auscultación

\footnotetext{
${ }^{63}$ Ibidem, pp. 72-79.

${ }^{64}$ OFICINA COMERCIAL DE ESPAÑA EN OSLO, SECRETARIA DE ESTADO DE COMERCIO, Informe Económico y Comercial. Noruega, 2016, URL:

< http://www.comercio.gob.es/tmpDocsCanalPais/2A7FE26A2DE57D417E428CDA6B54C37B.pdf> [consultado el 5 de mayo 2018].
} 
seleccionado es también cuando se está fraguando el corpus de lo que hoy conocemos como Unión Europea.

Con los parámetros de partida establecidos, el desarrollo del análisis aquí expuesto, en torno al factor común del Turismo Rural, arroja unos resultados parejos para Andalucía y Noruega; pese a tener ambos territorios fundamentaciones estructurales tan diferentes. Los datos obtenidos en esta inicial aproximación, a modo de balance, los podríamos agrupar en apartados temáticos bien definidos que, a su vez, servirían, más adelante, de indicadores de examen:

El binomio población y elemento territorial supone una base fundamental para ambos equipos gubernamentales: siendo que, Noruega, a través de la actividad turística rural, busca asimismo cohesión territorial, para afrontar su baja densidad de población $(17 \mathrm{~h} / \mathrm{Km} 2)$, así como el incremento de la despoblación juvenil en estas zonas; por su parte, Andalucía combate también la despoblación de los núcleos rurales, debido al éxodo urbano juvenil.

Coinciden, Noruega y Andalucía, en basar su política de fomento del Turismo Rural en principios como la formación e innovación; la cooperación entre los sectores públicos y privados; el desarrollo de la sociabilidad, así como en la convergencia con las líneas de actuación de la Unión Europea, en cuanto a la temática.

La coyuntura económica está también detrás de la convergencia de actuaciones de Noruega y Andalucía, a favor de la industria turística rural: si para la primera resulta imperioso buscar alternativas a los ingresos petrolíferos, dado su descenso de los últimos años -su incidencia en el PIB ha bajado en cuatro puntos porcentuales, entre 2014 y 2016, según los últimos datos de la Oficina Comercial de España en Oslo-65, y que además contribuyan a reactivar la economía autóctona, en un amplio espectro; para Andalucía supone una manera de reconversión agrícolaganadera, en las zonas rurales más deprimidas.

Igualmente convergen Noruega y Andalucía a la hora de inclinarse por impulsar políticas de igualdad de género, de cara al desarrollo del Turismo Rural, en sus territorios, dada la diversidad de factores concomitantes que se impulsan con ello.

\footnotetext{
${ }^{65}$ Ibidem.
} 


\section{EL AUTOR}

Gloria PRIEGO-DE-MONTIANO, es Profesora Docente e Investigadora de la Universidad de Córdoba (España). Ha conseguido un máster en "Género e Igualdad», por la Universidad Pablo de Olavide de Sevilla; fue adscrita al Departamento de Historia Moderna, Contemporánea y de América, de la Universidad de Córdoba (1997-2009), a la Cátedra de Mayores de la misma (2009-2012), donde ocupó la responsabilidad de «Gestora de Proyectos», y al Departamento de Didáctica de las Ciencias Sociales y Experimentales, de la citada Universidad (de 2012 a la actualidad). Ha participado en diversos Proyectos Europeos de Investigación y de «Excelencia», de la Junta de Andalucía, sobre temáticas socioeconómicas y educativas. Forma parte de la Junta Directiva de la «Asociación de Mujeres Investigadoras y Tecnólogas de Andalucía», así como es participante en otras asociaciones científicas.

URL: < http://www.studistorici.com/progett/autori/\#Priego-de-Montiano > 